UCRL-ID-125863

\title{
Interpretation of $f(\varepsilon)$ measurements by \\ T. Kimura, K. Akatsuka and K. Ohe
}

\author{
M. Garcia
}

November 26, 1996

This is an informal report intended primarily for internal or limited external distribution. The opiniens and conclusions stated are those of the author and may or may not be those of the Laboratory.

Work performed under the auppices of the U.S. Department of Energy by the Lawrence Livermore National Laboratory under Contract W-7405-Eng-\&. 


\section{DISCLAMER}

This document was prepared as an sccount of work sponsored by an agency of the United States Covernment. Nelther the United States Government nor the Univeraity of Cnlifornia nor any of their employees, makes any warranty, expreas or implied, or asumes any legal Hability or responsibility for the eccuracy, completeness, or usefulnes of any information, apparatus, product, or process disclosed, or represents that its we would not infringe privaldy owned rights. Beference herein to any specific commencial product, process, or service by trade nane, trademark, mmufacturer, or otherwise, does not necesearily conthute or imply th endorement, recommendetion, or favoring by the United States Government or the Univeretty of Calliomia. The views and opinions of authors expreseed herein do not necessarily state or reflect those of the Unibed States Government or the University of California, and shall not be ueed for advertiding or product endorsement purposes.

This report has been reproduced directly from the beat avallable copy.

Available to DOE and DOE contractors from the

Office of Scientific and Technical Information

P.O. Box 62, Oik Rddge, TN 37831

Prices aveiluble from (615) 576-8401, FTS 626-8401

Available to the public from the

National Technical Information Service

U.S. Depertment of Commerce

5285 Port Royal Rd.,

Springfield, VA 22161 


\title{
Interpretation of $f(\varepsilon)$ measurements by T. Kimura, K. Akatsuka, and K. Ohe
}

\author{
Manuel Garcia \\ 26 November 1996 \\ Lawrence Livermore National Laboratory \\ L-490, P.0.Box 808 Livermore, CA 94550 \\ (510) 422-6017, garcia22 ellnl.gov
}

\section{Introduction}

This note describes my analysis of the measurement of the electron energy distribution function in a $\mathrm{DC}$ glow discharge reported by T. Kimura, K. Akatsuka, and K. Ohe', in "Experimental and theoretical investigations of DC glow discharges in argon-nitrogen mixtures," J. Phys. D: Appl. Phys. 27 (1994) 1664-1671. T. Kimura of the Department of Systems Engineering at the Nagoya Institute of Technology sent me this paper in 1994, as well as 2 "Electron Energy Distribution Function in Neon-Nitrogen Mixture Positive Column," T. Kimura, and K. Ohe, Jpn. J. Appl. Phys. Vol. 31, Part 1, No. 12A, December 1992, pp. 4051-4052.

I base my analysis on the data for a pure $\mathrm{N}_{2}$ discharge at $\mathrm{p}=1$ torr in the 1994 paper $^{1}$. Figures 2 and 3 in that paper show a discrepancy between $f(\varepsilon)$ as measured by Langmuir probing and $f(\varepsilon)$ as calculated from $\mathrm{E} / \mathrm{N}$ based on the measured axial field. Kimura et. al. explain their observation of hotter than expected electrons on superelastic collisions with vibrationally excited nitrogen. My fundamental point is that the radial field generated by ambipolar diffusion significantly augments $E / N$ above the contribution from the axial field in this experiment, and creates a higher than expected radially averaged electron energy.

\section{Model of the experimental positive column}

The discharge tube has an inner radius $R=0.9 \mathrm{~cm}$, at $p=1$ torr of pure nitrogen, with current $\mathrm{I}=100 \mathrm{~mA}$, a measured average electron energy $\varepsilon=3 \mathrm{eV}$, and a measured average electron number density of $4 \times 10^{10} \mathrm{~cm}^{-3}$. 
From the classical positive column analysis the radial electron density profile is given by a zeroth order Bessel function with a peak at $r=0$ of $9.3 \times 10^{10} \mathrm{~cm}^{-3}$, and the first Bessel zero (2.405) at $\mathrm{r}=\mathrm{R}$. The radial average here is $4 \times 10^{10} \mathrm{~cm}^{-3}$. The resulting radial electric field magnitude can be shown to be:

$$
E=\frac{J_{1}\left(2.405 \frac{r}{R}\right)}{J_{0}\left(2.405 \frac{r}{R}\right)} \frac{2.405}{R} T_{e}
$$

for electron temperature expressed in $\mathrm{eV}$ and equivalent to $\mathrm{D}_{\mathrm{e}} / \mu_{\mathrm{e}}$. and where zeroth and first order Bessel functions are involved. The radial electric field is zero on the axis and infinite at $R$. Naturally, before the field becomes infinite quasineutrality breaks down and an electrostatic sheath coats the inner discharge tube wall.

The electric field across this sheath can be estimated as $T_{e}$ across a Debye length $h_{D}$. The Debye length in turn is assumed to result from $3 \mathrm{eV}$ electrons at a density about one tenth of the tube average, or $4 \times 10^{9} \mathrm{~cm}^{-3}$. This estimate produces $h_{D}=0.0203 \mathrm{~cm}$ and Debye field $E_{D}=147 \mathrm{~V} / \mathrm{cm}$. The electron-neutral mean free path is comparable at $\lambda_{e}=0.028 \mathrm{~cm}$. The transition between ambipolar flow and the wall sheath is designated as radius $r_{D}$, which is taken as the root of equation (1) where $E=E_{D}=147 \mathrm{~V} / \mathrm{cm}$. This is found to be $r_{D}=0.879 \mathrm{~cm}$, and as this all results in $R-r_{D}=1.014 \mathrm{~h}_{D}$, the original estimate of plasma density near the wall is shown to be quite reasonable. The radially averaged radial electric field in the ambipolar zone is found to be $12.1 \mathrm{~V} / \mathrm{cm}(10.7$ volts across $0.879 \mathrm{~cm}$, then 3 volts across the sheath). Figure 1, below, shows the profile.

\section{Calculating $f(\varepsilon)$ and $\varepsilon$ as functions of radius}

The probes used in the experiment were cylinders of $0.01 \mathrm{~cm}$ diameter and $0.15 \mathrm{~cm}$ length, spaced $5.3 \mathrm{~cm}$ apart on the tube axis. The tube radius, probe length, probe diameter and electron mean free path are in a ratio: $R: L_{p}: r_{p}: \lambda_{e}=32: 5.4: 0.4: 1$. The Debye length at the tube wall is comparable to the electron mean free path, and diminishes on approach to the axis. The ratio of tube radius to mean free path is small enough to interpret probe measurements as indicative of conditions averaged over the tube cross section. 


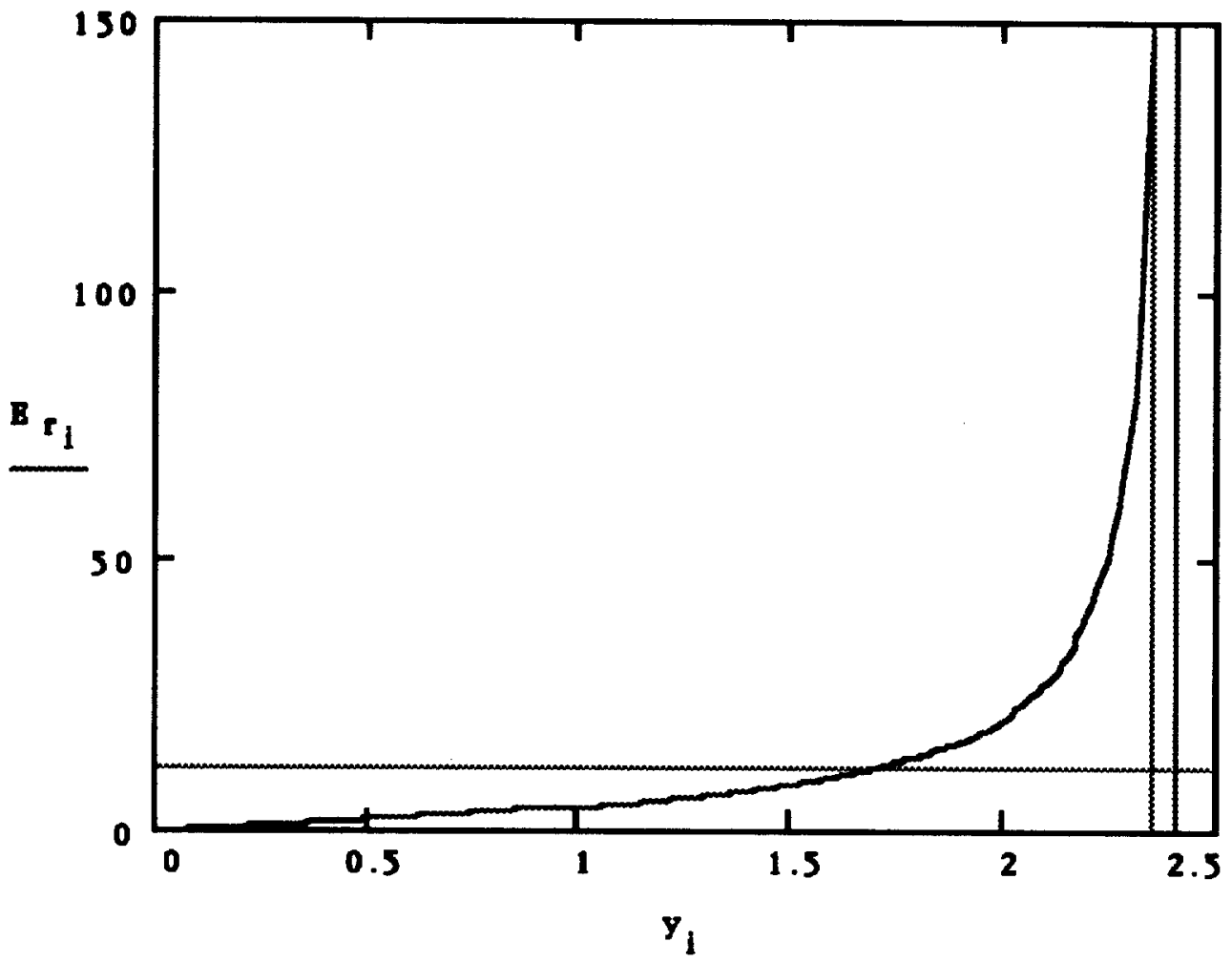

Figure 1: Radial electric field $(\mathrm{V} / \mathrm{cm})$ along radial coordinate $(-2.405 \mathrm{r} / \mathrm{R})$, with ambipolar average $(12.1$ $V / c m$ ), and the extent of the wall sheath shown. (" $i$ " is an index of data points used in the plots). $\mathrm{B} / \mathrm{N}$ based on this plot peaks at 417 Townsends ( $\mathrm{Td}=10^{-17} \mathrm{~V}$ $\mathrm{cm}^{2}$ ) with an ambipolar average of $34 \mathrm{Td}$. Axial $\mathrm{E} / \mathrm{N}$ is $50.85 \mathrm{Td}$. 
Figure 2, below, shows the net E/N given by the vector summation of radial and axial magnitudes. The resulting average is 61 Townsends. I would calculate an average electron energy in pure nitrogen of $1.3 \mathrm{eV}$ at $50 \mathrm{Td}$, and $2 \mathrm{eV}$ at $90 \mathrm{Td}$, a nearly linear relationship. This is in reasonable agreement with the expectation of Kimura et. al. of 1.5 to $2 \mathrm{eV}$ (depending on vibrational temperature) at $51 \mathrm{Td}$ axially, and their measured $3 \mathrm{eV}$ which $\mathrm{I}$ see as due to an increase in net $\mathrm{E} / \mathrm{N}$ because of the radial field.

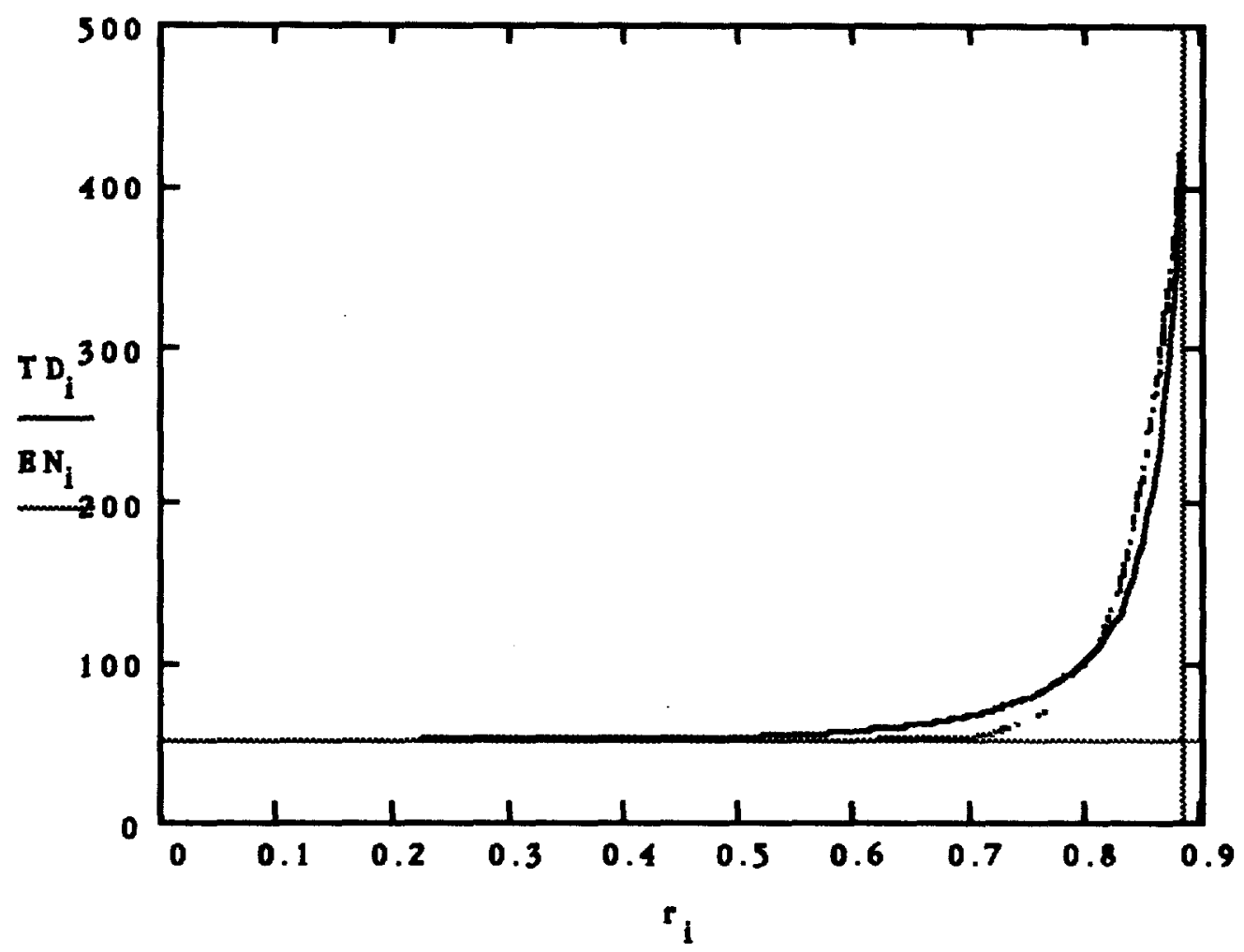

Figure 2: Net $E / N(T d)$ at radius $(\mathrm{cm})$ : vector sum of radial and axial $(50.85 \mathrm{Td})$ magnitudes. Horizontal line at $50.85 \mathrm{Td}$. Dotted line is an exponential profile with $1 /$ e length of $0.04 \mathrm{~cm}$ ( 1.4 mean free paths). 
Using the exponential E/N profile of Figure 2, I calculate the average electron energy as a function of distance from the inner edge of the wall sheath towards the axis by a method described previously 3,4. Figure 3 shows the result.

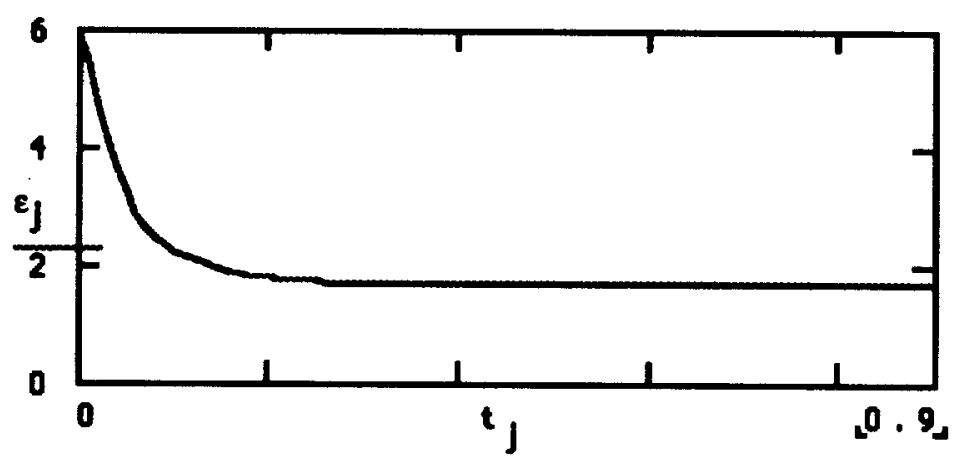

Figure 3: calculated average electron energy (eV) at distance $(\mathrm{cm})$ from wall sheath given exponential $\mathrm{E} / \mathrm{N}$ of Figure $2(22.5 \mathrm{e}$-folds $=0.9 \mathrm{~cm})(" \mathrm{j}$ " is another data point index, " $\mathrm{t}$ " is a distance parameter name, line above " 2 " is just a tag identifying " $\varepsilon$ " with the line)

Defining the area-averaged energy (here $T_{v}=0$ ) as:

$$
\varepsilon_{\text {ave }}=\frac{\int_{0}^{r_{D}} \varepsilon(r) 2 \pi r d r}{\pi r_{D}^{2}}
$$

then for Figure 3 the result of equation (2) is $\varepsilon_{\text {ave }}=2.16 \mathrm{eV}$ within the ambipolar zone (the inner $95.4 \%$ of the cross section). If an outer annulus at $0.021 \mathrm{~cm}$ ( $4.6 \%$ of the cross section) and $6 \mathrm{eV}$ is included, then $2.34 \mathrm{eV}$ is the cross section average energy. It is not hard to visualize an area-averaged electron energy of $3 \mathrm{eV}$ given the profiles in Figures 2 and 3 , in combination with superelastic collisions with excited nitrogen. Because the exponential for $m$ is easier to calculate then the Bessel form it was used to generate numbers for this example, also I used simplified cross sections to represent nitrogen.

Sample electron energy distribution functions at various distances from the wall sheath (at various radii in the ambipolar zone) are shown below in Figure 4. The "averaged" $f$ in Figure 4 
(like equation (2)) is generally similar to the Kimura et. al. measured $f$ in Figure 2 of reference (1), while the "steep" $f$ of Figure 4 is generally similar to the f expected by Kimura by his calculations based on arial $\mathrm{E} / \mathrm{N}$.

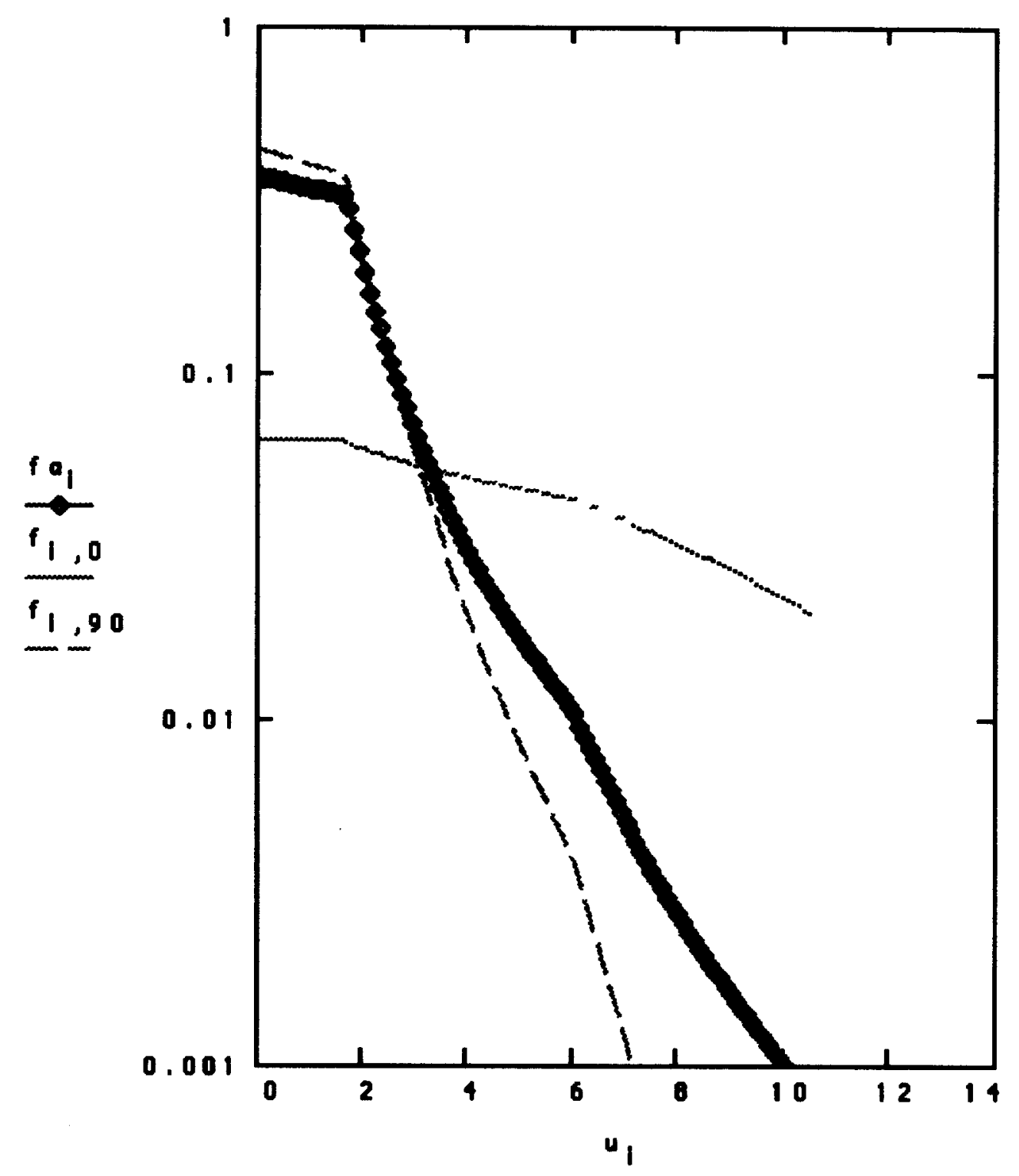

Figure 4: electron energy distribution functions (eV-3/2 vs. eV). The heavy line is the area-averaged $f(\varepsilon)$ over the ambipolar zone $(0.879>\mathrm{r})$, with $\varepsilon_{\mathrm{ave}}=$ $2.16 \mathrm{eV}$. The steep $\mathrm{f}$ has axial $\mathrm{B} / \mathrm{N}(\mathrm{r}-0 \mathrm{~cm})$ and $\varepsilon-$ $1.7 \mathrm{eV}$, and the shallow $\mathrm{f}$ occurs close to the wall sheath $(r-0.879 \mathrm{~cm})$ where $\varepsilon=6 \mathrm{eV}$ in Figure 3 . 


\section{Conclusion}

The relative narrowness of the discharge tube $\left(R / \lambda_{e}=32\right)$ in the experiment produced a significant radial electric field that augmented local E/N significantly above the contribution from the axial positive column field. I believe that both the measurements and calculational method used by Kimura, Akatsuka and Ohe were quite accurate, but that too low a value of $\mathrm{E} / \mathrm{N}$ was used in the calculations. Experiments in a wider discharge tube $\left(R / \lambda_{e} \gg 32\right)$ would help to separate the effects on $f(\varepsilon)$ of radial $E / N$ and superelastic collisions with vibrationally excited nitrogen.

\section{Acknowledgments}

I am grateful to T. Kimura for sending me references (1) and (2). I found these to be very interesting papers, and carefully crafted work.

\section{References}

(1) T. Kimura, K. Akatsuka, and K. Ohe, "Experimental and theoretical investigations of DC glow discharges in argonnitrogen mirtures," J. Phys. D: Appl. Phys. 27 (1994) 16641671 .

(2) T. Kimura, and $\mathbf{K}$ Ohe, "Electron Energy Distribution Function in Neon - Nitrogen Mirture Positive Column," Jpn. J. Appl. Phys. Vol. 31, Part 1, No. 12A, December 1992, pp. 4051 - 4052.

(3) M. Garcia, "Molecular Gas Electron Distribution Function with Space and Time Variation," UCRL-ID-121161, May 1995.

(4) M. Garcia, "Analytical Boltzmann Moments for Electrons in $\mathrm{N}_{2}$ $\mathrm{O}_{2}-\mathrm{H}_{2} \mathrm{O}$ Gas Mixtures," IEEE International Conf. on Plasma Science, 6-8 June 1994, Santa Fe, NM, (UCRL-ID-1 17124, A pril 1994).

see (3), (4) electronically: http://www.llnl.gov/tid/lof/lof_home.htm1 


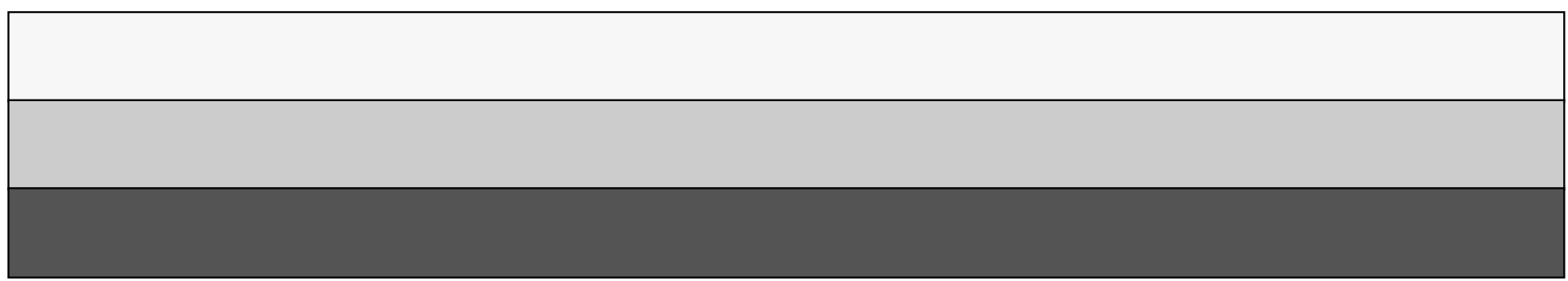

